\title{
Development and characterization of iron-pectin beads as a novel system for iron delivery to intestinal cells
}

\author{
F. Ghibaudo ${ }^{a}$, E. Gerbino ${ }^{a}$, A.A. Hugo ${ }^{a}$, M.G. Simões ${ }^{b}$, P. Alves ${ }^{b}$, B.F.O. Costa $^{c}$, \\ V. Campo Dall' Orto ${ }^{\mathrm{d}, \mathrm{e}}$, A. Gómez-Zavaglia ${ }^{\mathrm{a}, *}$, P.N. Simões ${ }^{\mathrm{b}}$ \\ ${ }^{\text {a }}$ Center for Research and Development in Food Cryotechnology (CCT-CONICET La Plata, UNLP) RA-1900, Argentina \\ ${ }^{\mathrm{b}}$ CIEPQPF, Department of Chemical Engineering, University of Coimbra, Polo II, Pinhal de Marrocos, P-3030-790 Coimbra, Portugal \\ c CFisUC, Physics Department, University of Coimbra, 3004-516 Coimbra, Portugal \\ d Department of Analytical Chemistry and Physical Chemistry, Faculty of Pharmacy and Biochemistry, University of Buenos Aires, Junín 956, 3rd Floor, RA 1113, \\ Argentina \\ e CONICET-Universidad de Buenos Aires, Institute of Chemistry and Drug Metabolism (IQUIMEFA), Junín 956, Buenos Aires, Argentina
}

\section{A R T I C L E I N F O}

\section{Keywords:}

Iron absorption and transport

Food fortification

Ionic gelation

Pectin

Iron

\begin{abstract}
A B S T R A C T
Iron deficiency is the most common nutritional deficit worldwide. The goal of this work was to obtain iron-pectin beads by ionic gelation and evaluate their physiological behavior to support their potential application in the food industry. The beads were firstly analyzed by scanning electronic microscopy, and then physical-chemically characterized by performing swelling, thermogravimetric, porosimetry, Mössbauer spectroscopy and X-ray fluorescence analyses, as well as by determining the particle size. Then, physiological assays were carried out by exposing the beads to simulated gastric and intestinal environments, and determining the iron absorption and transepithelial transport into Caco-2/TC7 cells.

Iron-pectin beads were spherical (diameter $1-2 \mathrm{~mm})$, with high density $(1.29 \mathrm{~g} / \mathrm{mL}$ ) and porosity $(93.28 \%)$ at low pressure, indicating their high permeability even when exposed to low pressure. Swelling in simulated intestinal medium ( $\mathrm{pH} 8$ ) was higher than in simulated gastric medium. The source of iron $\left[\mathrm{FeSO}_{4}\right.$ (control) or iron-pectin beads] did not have any significant effect on the mineral absorption. Regarding transport, the iron added to the apical pole of Caco-2/TC7 monolayers was recovered in the basal compartment, and this was proportional with the exposure time. After $4 \mathrm{~h}$ of incubation, the transport of iron arising from the beads was significantly higher than that of the iron from the control $\left(\mathrm{FeSO}_{4}\right)$. For this reason, iron-pectin beads appear as an interesting system to overcome the low efficiency of iron transport, being a potential strategy to enrich food products with iron, without altering the sensory properties.
\end{abstract}

\section{Introduction}

Iron deficiency is the most common nutritional deficit worldwide and represents a public health problem in both industrialized and nonindustrialized countries. Iron is an essential trace metal for all organisms. In humans, it plays important biochemical roles, including the binding of oxygen to hemoglobin or as catalytic center of many enzymes (e.g., cytochromes). The iron concentration in the body is regulated at absorption level in the proximal small intestine [1]. The daily requirements of dietary iron are 5-30 $\mathrm{mg}$, depending on the stage of growth, gender and diet. Dietary iron occurs in two forms, as heme iron from meat products, and as non-heme (inorganic) iron present in vegetables and derivatives. The bioavailability of heme iron is $20-30 \%$, and that of non-heme one is only 1-10\% [2].

To overcome the above mentioned public health problem, supplementation and/or fortification are two strategies generally used for correcting iron deficiency. The first one is targeted to high-risk population. Iron is provided three or four times a day in high doses (usually $60 \mathrm{mg} \mathrm{Fe} /$ day), and is not included in food products. This strategy often carries unwanted effects, such as abdominal pain, constipation, diarrhea and vomiting. On the contrary, fortification might be a safer intervention because iron is included in food in lower doses, simulating the physiological environment and avoiding the undesirable side effects [3]. Ferrous sulfate and fumarate sulfate are the most bioavailable iron

Abbreviations: DLS, dynamic light scattering; DMEM, Dulbecco's modified Eagle medium; PBS, phosphate buffered saline; SEM, scanning electronic microscopy; TGA, thermogravimetric analysis; XRF, X-ray fluorescence analysis; $\zeta$, zeta potential

* Corresponding author at: Calle 47 y 116 La Plata, Buenos Aires RA1900, Argentina.

E-mail address: angoza@qui.uc.pt (A. Gómez-Zavaglia). 
compounds. Although they are soluble in water or diluted acid, they often react with other food components to cause off-flavors, color changes or fat oxidation [4]. For this reason, encapsulated ferrous sulfate and fumarate are available in the market for food fortification, preventing iron atoms to alter food sensory properties, and enabling iron to be safely released and absorbed in the small intestine. Therefore, although less soluble forms of iron are less well absorbed, they are often chosen for fortification to avoid undesired sensory changes [4].

An alternative method to prevent this undesirable effect of iron in fortified foods is ionic gelation, through which polymeric beads are obtained using divalent cations. In ionic gelation, cations form insoluble associates with carbohydrate chains, resulting in the so-called "egg-box" complexes [5]. Natural biopolymers, including dietary oligo and polysaccharides, are particularly interesting for this purpose because of their good biocompatibility, non-toxicity and controlled release properties [6]. Pectins are linear chains of partially methyl-esterified $(1 \rightarrow 4)$-linked $\alpha$-D-galacturonic acid residues. Those of low degree of esterification $(<50 \%)$ are useful for ionotropic gelation [7]. As pectins belong to dietary fiber, they are not hydrolyzed in the upper part of the gastro-intestinal tract. For this reason, pectin matrices have been widely used to deliver drugs whose target is the colon [8-11]. Calcium and zinc have been majorly employed as divalent cations for ionotropic gelation, but the use of iron in that function has been very scarcely addressed [12].

Although most dietary iron is absorbed in the duodenum, the colon mucosa also expresses the iron absorption proteins, thus enabling the absorption of $30 \%$ of the iron present in the gastrointestinal tract [13]. Non-digestible carbohydrates (e.g., pectins, inulins), resist digestion in the small intestine but are fermented in the colon to short-chain fatty acids, with a variety of health benefits, including the enhancement of iron absorption [14].

Considering the important role of ferrous sulfate salts to enhance iron consumption, the goal of this work was to develop iron-pectin beads by ionotropic gelation as a novel strategy for food fortification. The beads were firstly observed by scanning electronic microscopy, and then physical-chemically characterized by performing swelling, thermogravimetric, porosimetry and X-ray fluorescence analyses. Afterwards, physiological assays were carried out by exposing the beads to simulated gastric and intestinal environments, and by determining the particle size, iron absorption and transepithelial transport in Caco2/TC7 cells, thus fulfilling a study that supports the safe delivery of iron to the gut.

\section{Materials and methods}

\subsection{Preparation of pectin beads}

Pectin from citrus peel (galacturonic acid $\geq 74.0 \%$, Sigma Aldrich, Buenos Aires, Argentina) was dissolved in $0.060 \mathrm{M}$ acetic acid-sodium acetate (Sigma Aldrich, Buenos Aires, Argentina) at pH 5.0, to obtain a $4 \% \mathrm{w} / \mathrm{v}$ solution. The pectin solution was dripped into a $150 \mathrm{mM} \mathrm{FeSO}_{4}$ solution using a $0.3 \mathrm{~mm}$ needle $(\sim 10 \mu \mathrm{L} / \mathrm{drop})$ under continuous agitation for $30 \mathrm{~min}$. The beads were harvested by filtration through a stainless-steel mesh of $0.10 \mathrm{~mm}$ and washed three times with distilled water. Then, the beads were frozen at $-80{ }^{\circ} \mathrm{C}$ and freeze-dried for $48 \mathrm{~h}$ on a Heto FD4 equipment (Heto Lab Equipment, Denmark) operating with the condenser at $-45^{\circ} \mathrm{C}$ at a chamber pressure of 0.04 mbar.

\subsection{Scanning electronic microscopy (SEM)}

The obtained beads were mounted on metal stubs with double sided adhesive carbon tape, coated with gold using a sputter coater (Polaron Thermo VGScientific, East Grinstead, Sussex, UK) under vacuum and $18 \mathrm{~mA}$ at room temperature [15]. The morphology of the beads was observed by SEM, focusing both on the inner and superficial features. Samples were examined using an environmental scanning electron microscope (FEI La B6, Eindhoven, Netherlands) at $14 \mathrm{kV}$ accelerating voltage with an electron detector for low vacuum conditions. For examination of the inner structure, the beads were cut in half with a steel blade.

\subsection{In vitro digestion}

The freeze-dried beads were digested in simulated gastrointestinal solutions (adapted from [16]). In brief, 10 beads (weighting about $3.5 \mathrm{mg}$, and representing about $100 \mu \mathrm{L}$ of the original pectin solution) were suspended for $2 \mathrm{~min}$ in $1 \mathrm{~mL}$ of saliva $[10 \mathrm{mg} / \mathrm{mL} \alpha$-amylase from Bacillus subtilis in phosphate buffered saline (PBS) $\left(\mathrm{K}_{2} \mathrm{HPO}_{4} 0.144 \mathrm{~g} / \mathrm{L}\right.$; $\mathrm{NaCl} 9.00$ g/L; $\mathrm{Na}_{2} \mathrm{HPO}_{4} 0.795 \mathrm{~g} / \mathrm{L}, \mathrm{pH}$ 6.8)] (Sigma Aldrich, St. Louis, MO, USA). Saliva was thoroughly removed, and then $1 \mathrm{~mL}$ of simulated gastric digestion $(3 \mathrm{mg} / \mathrm{mL}$ porcine pepsin, $125 \mathrm{mM} \mathrm{NaCl}, 7 \mathrm{mM} \mathrm{KCl}$, $45 \mathrm{mM} \mathrm{NaHCO}$, $\mathrm{pH}$ 2.5) (Sigma Aldrich, St. Louis, MO, USA) was added to the sedimented beads. Samples were incubated for $1.5 \mathrm{~h}$ at $37^{\circ} \mathrm{C}$ under continuous gentle shaking ( $50 \mathrm{rpm}$, MaxQ 4000, Thermo Scientific, USA). Afterwards, the gastric juice was thoroughly removed and $1 \mathrm{~mL}$ of simulated intestinal juice $(1 \mathrm{mg} / \mathrm{mL}$ pancreatin, $1.5 \mathrm{mg} / \mathrm{mL}$ bile salts, $22 \mathrm{mM} \mathrm{NaCl}, 3.2 \mathrm{mM} \mathrm{KCl}, 7.6 \mathrm{mM} \mathrm{NaHCO}_{3}, \mathrm{pH}$ 8.0) (Sigma Aldrich, St. Louis, MO, USA) was added to the beads and incubated for $3 \mathrm{~h}$ at $37^{\circ} \mathrm{C}$, under continuous gentle shaking (50 rpm, MaxQ 4000, Thermo Scientific, USA).

\subsection{Swelling characterization of the beads}

Freeze-dried beads were weighed on an analytical balance (Adventurer Ohaus, Parsippany, NJ, USA balance sensitivity: $0.1 \mathrm{mg}$ ), and then hydrated for $15 \mathrm{~min}$ in water and for $60 \mathrm{~min}$ in the simulated gastric and intestinal solutions. Afterwards, the beads were dried for 5 min at $20^{\circ} \mathrm{C}$ on cellulose paper (Whatman $n^{\circ} 1$ ) and weighed again.

The degree of swelling (given by the ability to absorb water in the interstices of the microspheres) was determined:

$\frac{W h-W d}{W d} \times 100$

where $W h$ is the weight of hydrated beads and $W d$, the weight of the dehydrated ones.

\subsection{Thermogravimetric analysis (TGA)}

The thermal stability of pectin and pectin-Fe samples was studied by High-Resolution-Modulated-Thermogravimetry Hi-Res-MTGA (TA Instruments Q500, USA; balance sensitivity: $0.1 \mu \mathrm{g}$ ). The temperature calibration was carried out by measuring the Curie point of nickel standard in open platinum crucibles, under a dry nitrogen purge flow of $100 \mathrm{~mL} / \mathrm{min}$, at a heating rate of $2{ }^{\circ} \mathrm{C} / \mathrm{min}$, a modulation period of $200 \mathrm{~s}$, and an amplitude temperature of $\pm 5^{\circ} \mathrm{C}$. Experiments were carried out in the $20-600^{\circ} \mathrm{C}$ temperature range.

\subsection{Mercury intrusion porosimetry}

The porosity and the pore size distribution of the freeze-dried beads were quantified by mercury intrusion porosimetry using the AutoPore IV 9500, from Micromeritics (Atlanta, USA), at a pressure of 0.5 and 30 psi.

\section{7. $X$-ray fluorescence analysis $(X R F)$}

Iron-pectin beads and commercial pectin powder (galacturonic acid $\geq 74.0 \%$, Sigma Aldrich, Buenos Aires, Argentina) were analyzed by Xray fluorescence. The measurements were undertaken in air at atmospheric pressure on a Hitachi SEA6000VX bench top high-sensitivity $\mathrm{XRF}$ analyzer, with an X-ray tube with a tungsten target, operating at potentials of 15 and $50 \mathrm{kV}$ and a current of $1000 \mathrm{~mA}$, and a $3 \mathrm{~mm}$ wide 
primary-beam collimator. The SEA6000VX measurement geometry was fixed, with its energy-dispersive Vortex Si semiconductor detector positioned at a scattering angle of $135^{\circ}$ and a distance of $19 \mathrm{~mm}$ from the specimen, with no additional slits to restrict its acceptance angle. Results were expressed as percentage of the normalized detected elements (light elements were not detected).

\subsection{Particle size and zeta $(\zeta)$ potential measurement}

Particle size measurements were performed in a Horiba Nano-SZ 100 analyzer (Horiba, Japan) at $37^{\circ} \mathrm{C}$. The average hydrodynamic particle size (Z-average) was determined by using dynamic light scattering at backward scattering $\left(173^{\circ}\right)$ with the Horiba software (Horiba NextGen Projet SZ100 for Windows).

$\zeta$-potential was determined using a combination of measurement techniques: Electrophoresis and Laser Doppler Velocimetry (Laser Doppler Electrophoresis). The $\zeta$-potential values were provided directly by the instrument. Average and standard deviation values of Z-average and $\zeta$-potential were obtained from at least 10 determinations for each sample.

\subsection{Mössbauer spectroscopy}

${ }^{57} \mathrm{Fe}$ Mössbauer measurements of smashed pectin beads were carried out in transmission geometry at $20^{\circ} \mathrm{C}$. A ${ }^{57} \mathrm{Co} / \mathrm{Rh}$ source with about $10 \mathrm{mCi}$ was used in a conventional constant acceleration mode Mössbauer spectrometer (WissEL). The spectrum was fitted by least square fitting of several lines using NORMOS program [17]. The isomer shifts are given relatively to $\alpha$-Fe.

\subsection{Culture of Caco-2/TC7 cells}

Human enterocyte Caco-2/TC7 cell line was cultured in Dulbecco's Modified Eagle Medium (DMEM) (Gibco BRL Life Technologies, Rockville, MD, USA), supplemented with $15 \% \mathrm{v} / \mathrm{v}$ heat-inactivated (30 min at $60{ }^{\circ} \mathrm{C}$ ) fetal bovine serum, $1 \% \mathrm{w} / \mathrm{v}$ non-essential amino acids and $1 \% \mathrm{v} / \mathrm{v}$ penicillin-streptomycin solution $(100 \mathrm{U} / \mathrm{mL}$ penicillin $\mathrm{G}$, $100 \mathrm{~g} / \mathrm{mL}$ streptomycin). Cultured cells were incubated at $37^{\circ} \mathrm{C}$, in a $5 \% \mathrm{CO}_{2}, 95 \%$ air atmosphere. During the experiments supplemented DMEM medium was replaced by DMEM medium without antibiotics or fetal bovine serum.

\subsection{Iron absorption by Caco-2/TC7 cells}

Caco-2/TC7 cells were seeded at ca. $2.0 \times 10^{5}$ cells $/ \mathrm{mL}$ onto $25 \mathrm{~cm}^{2}$ culture flasks. Cells were maintained under the culture conditions described above and used at 7-8 days post-seeding for the Fe uptake experiments. Prior to the experiment, cell monolayers were washed twice with PBS. Then, fresh DMEM containing a final concentration of 200 $\mu \mathrm{M}$ Fe (as a solution of digested $\mathrm{FeSO}_{4}$ or a solution of digested iron beads) was added. Cells were incubated with the different Fe solutions or control DMEM medium at $37{ }^{\circ} \mathrm{C}$ for 2,4 and $6 \mathrm{~h}$. After each incubation period, the medium was removed and cell monolayers were washed twice with $2 \mathrm{mM}$ PBS-EDTA to eliminate any Fe loosely adhered to cell membranes. Then, ultrapure water was added and the monolayers were mechanically removed with cell scrappers. Cell suspensions were sonicated in a Sonic Ruptor 400 ultrasonic homogenizer (OmniInternational, Georgia, USA) at $40 \%$ of amplitude with 3 burst cycles of $15 \mathrm{~s}$ maintaining the sample at $4^{\circ} \mathrm{C}$. Cell lysates were frozen at $-80^{\circ} \mathrm{C}$, freeze-dried and resuspended in ultrapure water to achieve a 15 times concentration of the original volume. The concentrated lysates were then used to determine the iron concentration. The freeze-drying process was carried out at $-50{ }^{\circ} \mathrm{C}$ and $0.04 \mathrm{mbar}$ in a Rificor L-A-B4-C freeze-dyer (Buenos Aires, Argentina).

\subsection{Transepithelial transport of the beads in Caco-2/TC7 cells}

Caco-2/TC7 cell monolayers were obtained by seeding $0.2 \mathrm{~mL}$ of Caco-2/TC7 cells onto polycarbonate membrane filters $(8.0 \mu \mathrm{m}$ pore size, $1.12 \mathrm{~cm}^{2}$ growth area) inside transwell cell culture chambers (Corning Costar Cambridge, MA, USA) at a density of $4 \times 10^{5}$ cells/ $\mathrm{cm}^{2}$, and cultured according to the procedure described in Sections 2.9 and 2.10. After 7 days, Caco-2/TC7 monolayers were confirmed by determining transepithelial electrical resistance using a Millicell-ERS system (MilliCell Corporation, Billerica, MA, USA). Cells with transepithelial electrical resistivity values of around $300-400 \Omega \mathrm{cm}^{2}$, were used for transepithelial transport studies. Before the experiment, monolayers were washed twice with PBS, and then the basolateral compartments were filled with $0.8 \mathrm{~mL}$ of fresh DMEM without fetal bovine serum. The apical compartment was filled with $0.2 \mathrm{~mL}$ of DMEM containing a final concentration of $200 \mu \mathrm{M} \mathrm{Fe}$ as a solution of digested $\mathrm{FeSO}_{4}$ (control) or as a solution of digested iron beads. Then, the transwell plate was incubated at $37^{\circ} \mathrm{C}$ for $2,4,6,8$ and $12 \mathrm{~h}$. After each incubation period, the total volume of the basolateral chamber was removed and frozen at $-80^{\circ} \mathrm{C}$. Basolateral frozen samples were freezedried as described in Section 2.1, and their content was suspended in 80 $\mu \mathrm{L}$ of ultrapure water, thus reaching a concentration 10 times higher than the original one.

\subsection{Measurements of iron uptake and basal transfer in Caco-2/TC-7cells}

Iron uptake and basal transfer to Caco-2/TC-7 cells were measured using the colorimetric assay of Fer-Color (Wiener Laboratories, Rosario, Argentina). Briefly, iron was reduced with mercaptoacetic acid and then, pyridil-bis-fenil-triazin sulfonate was used to complex the reduced iron. The absorbance of the colored complex was measured at $560 \mathrm{~nm}$ in a Synergy HT fluorescence microplate reader (Bio-Tek Instruments, Winoski, Vermont, USA).

\subsection{Reproducibility of results}

All experiments were performed on duplicate samples using three independent preparations. The relative differences were reproducible irrespective of the preparation employed. Analysis of variance (ANOVA) was carried out using the Infostat v2009 statistical software (Córdoba, Argentina). Differences were tested with paired sample $t$ tests, and if $\mathrm{p}<0.05$ the difference was considered statistically significant.

\section{Results and discussion}

\subsection{Physical and chemical characterization of the beads}

Iron-pectin beads were spherical, with a diameter within 1 and $2 \mathrm{~mm}$, with a rather smooth external surface, whose inner structure showed a compact texture with regularly observable holes (Fig. 1).

The swelling degree is a crucial factor in the release of drugs from delivery systems. For iron-pectin beads, the swelling behavior of the beads showed to be dependent on $\mathrm{pH}$ of the medium (Fig. 2). The beads swelled less when exposed to the acidic gastric medium ( $\mathrm{pH} 1.25)$. In agreement with refs. [18,19], swelling was higher in simulated intestinal medium ( $\mathrm{pH}$ 8) than in simulated gastric medium. This opposite behavior can be explained on the basis of the mutual repulsion between the negative charges of carboxylic groups $\left(-\mathrm{COO}^{-}\right)$[20]. As pectins are anionic polyelectrolytes, the $\mathrm{pH}$ changes of the environment affect their conformation [21]. In acidic media, there is a predominance of $\mathrm{H}^{+}$ions that leads to protonation of carboxyl groups, thus reducing electrostatic repulsion. Hence, polymer chains become tighter, making difficult the penetration of liquid in the system and reducing the solubility of the polymer chains $[19,22]$. At higher $\mathrm{pH}$ values carboxyl groups remain in the ionized form, which increases the hydrophilicity 

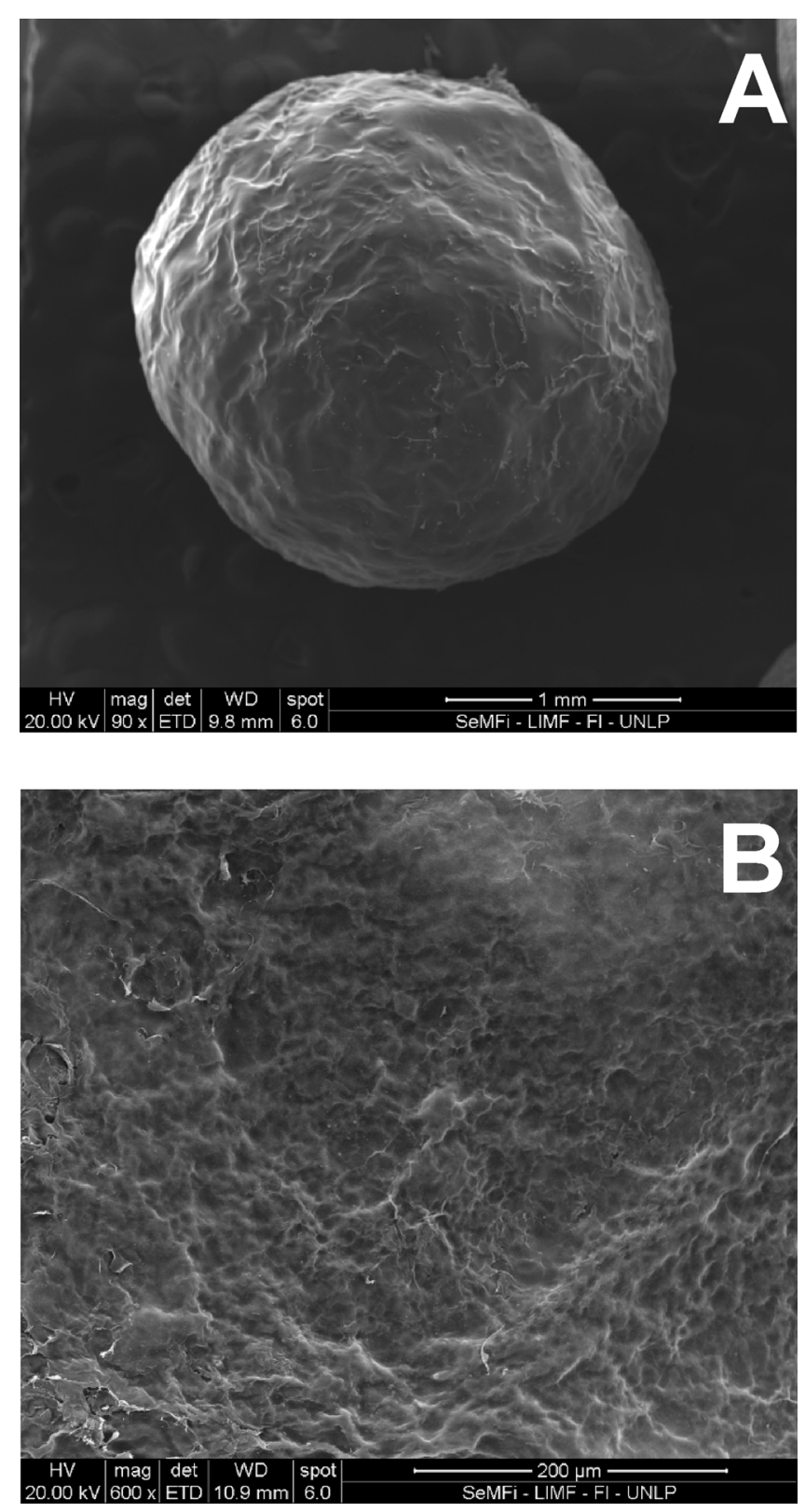

Fig. 1. Scanning electron microscope pictures of: A. External surface of ironpectin beads. B. Inner structure of iron-pectin beads.

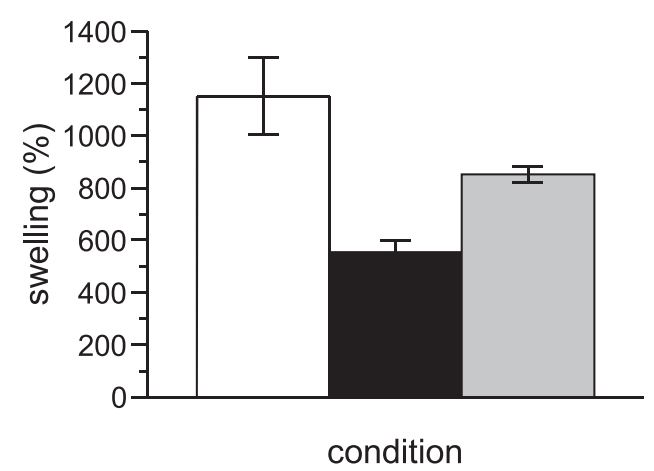

Fig. 2. Percentage of swelling after exposing the beads to water (white bar) or simulated gastric (black bar) or intestinal (gray bar) solutions for $60 \mathrm{~min}$.
Table 1

Mercury intrusion porosymetry of iron-pectin beads.

\begin{tabular}{lll}
\hline Pressure range (psi) & $0.5-33,000$ & $30-33,000$ \\
\hline Total pore area $\left(\mathrm{m}^{2} / \mathrm{g}\right)$ & 3.51 & 2.08 \\
Median pore diameter (volume) & $30.19 \mu \mathrm{m}$ & $1.51 \mu \mathrm{m}$ \\
Median pore diameter (area) & $1.83 \mu \mathrm{m}$ & $0.72 \mu \mathrm{m}$ \\
Average pore diameter (4 V/A) & $12.27 \mu \mathrm{m}$ & $1.01 \mu \mathrm{m}$ \\
Bulk density at initial pressure $(\mathrm{g} / \mathrm{mL})$ & 0.087 & 0.087 \\
Apparent density $(\mathrm{g} / \mathrm{mL})$ & 1.29 & 0.09 \\
Porosity & $93.28 \%$ & $4.56 \%$ \\
\hline
\end{tabular}

and promotes the network expansion as result of the electrostatic repulsion. Both factors favor the penetration of liquid in the system [22]. Therefore, the polymers show greater swelling ability at $\mathrm{pH} 8$ (the intestinal medium). This behavior can be ascribed to the presence of hydroxyl anions in the medium, which may favor the release of Fe(II), acting as cross-linking points of the pectin chains, thus resulting in the increase of water uptake by these systems [23].

The porosity of iron-pectin beads was determined by mercury intrusion porosimetry using two ranges of pressure (Table 1). In the low pressures range (0.5-33000 psi), the interstices (inter-particle spaces) were the main contributors to porosity. In turn, in the range of high pressures, porosity was mainly determined by the pores (intra-particle space). This explains the disparity between the results presented in Table 1, which are ascribed to the interstices. In fact, the beads showed low density $(0.09 \mathrm{~g} / \mathrm{mL})$ and no significant porosity $(4.56 \%)$ at high pressure. On the contrary, higher density $(1.29 \mathrm{~g} / \mathrm{mL})$ and high porosity (93.28\%) were observed at low pressure, indicating that the beads are highly permeable even when exposed to low pressure.

The chemical composition of iron-pectin beads and commercial citrus pectins was measured by XRF (Table 2). The results clearly indicate the large increase in the amount of iron after encapsulation. The decrease in the amount of the intrinsic cations of the commercial pectin powder $\left[\mathrm{Cu}(\mathrm{II}), \mathrm{K}^{+}\right]$can be ascribed to their exchanged with $\mathrm{Fe}(\mathrm{II})$ on ion gelation. $\mathrm{Fe}$ (II) resulted entrapped in the beads, and sulfate ions from the salt were also retained in some extent.

Fig. S1 shows the Mössbauer spectrum of Fe pectin beads recorded at $20^{\circ} \mathrm{C}$. The spectrum can be decomposed into three doublets, D1, D2 and D3 (Table 3), corresponding to Fe(II) (D1 and D2) and Fe(III) ions (D3). Fe(II) ions were the main component $(71.5 \%)$ of the spectrum, occurring in two ferrous microenvironments. In a previous work, however, the iron released from the beads was identified as Fe(III) by colorimetric method, carried out in an aqueous solution [12] (contrarily to the Mössbauer experiments, in which smashed samples were used). This seems to indicate that the ferrous form released from the beads was oxidized in aqueous solution.

The TGA curves of iron-pectin beads and commercial pectins (controls) are shown in Fig. 3, and some their characteristic quantities, in

Table 2

XRF-analysis of the iron-pectin beads and commercial citrus pectin powder. Relative values are reported. They were calculated considering detectable elements.

\begin{tabular}{lll}
\hline Element (\%) & Iron-pectin beads & Commercial pectin powder \\
\hline $\mathrm{S}$ & $20.28 \pm 0.53$ & n.d. \\
$\mathrm{Cl}$ & $0.61 \pm 0.18$ & n.d. \\
$\mathrm{Ca}$ & $0.66 \pm 0.09$ & $64.27 \pm 1.43$ \\
$\mathrm{Cr}$ & $0.24 \pm 0.02$ & n.d. \\
$\mathrm{Mn}$ & $0.30 \pm 0.03$ & n.d. \\
$\mathrm{Fe}$ & $77.77 \pm 0.23$ & $3.00 \pm 0.30$ \\
$\mathrm{Cu}$ & $0.03 \pm 0.02$ & $0.42 \pm 0.09$ \\
$\mathrm{Zn}$ & $0.06 \pm 0.02$ & $0.30 \pm 0.06$ \\
$\mathrm{Br}$ & $0.06 \pm 0.01$ & n.d. \\
$\mathrm{K}$ & n.d. & $32.01 \pm 0.67$ \\
\hline
\end{tabular}

n.d.: not detected. 
Table 3

Mössbauer parameters obtained by fitting the spectrum shown in Figure S1.

\begin{tabular}{lllll}
\hline Doublet & $\begin{array}{l}\text { Isomer shift }(\mathrm{mm} / \\
\mathrm{s})\end{array}$ & $\begin{array}{l}\text { Quadrupole splitting } \\
(\mathrm{mm} / \mathrm{s})\end{array}$ & Area (\%) & Assignment \\
\hline D1 & $0.60 \pm 0.02$ & $1.68 \pm 0.01$ & 43.1 & $\mathrm{Fe}(\mathrm{II})$ \\
D2 & $0.92 \pm 0.02$ & $1.81 \pm 0.01$ & 28.4 & $\mathrm{Fe}(\mathrm{II})$ \\
D3 & $0.45 \pm 0.01$ & $0.49 \pm 0.01$ & 28.5 & $\mathrm{Fe}(\mathrm{III})$ \\
\hline
\end{tabular}
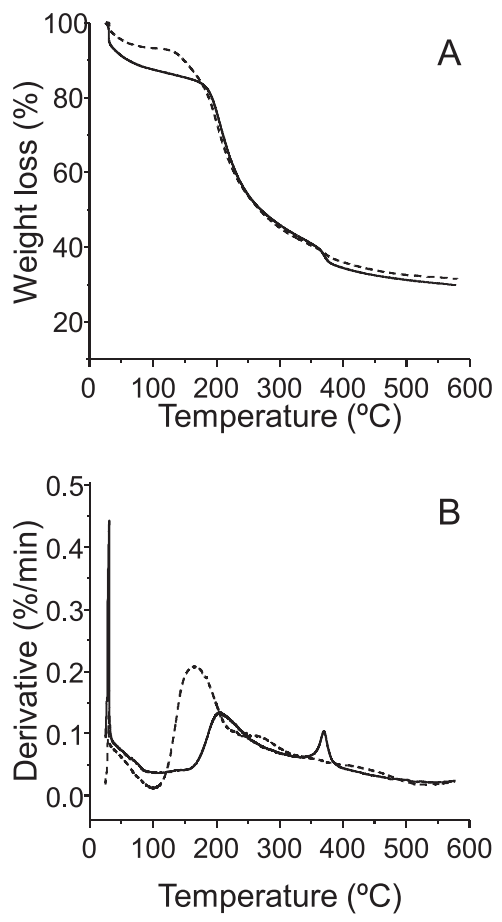

Fig. 3. High resolution modulated thermogravimetric analysis of iron-pectin beads (full lines) and commercial pectin powder (dash lines): A. Weight loss vs temperature. B. Derivate of weight loss vs temperature.

Table 4

Characteristic values (average of at least two runs \pm SD) obtained from the TG curves: $\Delta m$ - mass loss in each relevant step; $T_{\text {on }}$ - extrapolated onset temperature; $m_{\text {res }}$ - residual mass.

\begin{tabular}{|c|c|c|c|c|}
\hline & \multirow{2}{*}{$\begin{array}{c}25<T / \\
{ }^{\circ} \mathrm{C}<150 \\
\Delta m(\%)\end{array}$} & \multirow{2}{*}{$\begin{array}{l}150<T / \\
{ }^{\circ} \mathrm{C}<300 \\
T_{\text {on }}\left({ }^{\circ} \mathrm{C}\right)\end{array}$} & \multicolumn{2}{|l|}{$T /{ }^{\circ} \mathrm{C}>300$} \\
\hline & & & $T_{\text {on }}\left({ }^{\circ} \mathrm{C}\right)$ & $m_{\mathrm{res}}(\%)$ \\
\hline pectin powder & $7.1 \pm 0.1$ & $174.6 \pm 0.5$ & - & $30.8 \pm 0.1$ \\
\hline $\begin{array}{l}\text { iron-pectin } \\
\text { beads }\end{array}$ & $13.6 \pm 0.1$ & $188.7 \pm 1.3$ & $363.6 \pm 0.4$ & $28.0 \pm 0.1$ \\
\hline
\end{tabular}

Table 4. Both beads and controls had similar mass loss profiles. The first step in the range $25-200^{\circ} \mathrm{C}$ (Fig. 3A) can be ascribed to the moisture loss from the polysaccharide structure [24]. The higher loss in the case of the iron-pectin beads (12.5\%) can be explained considering that they were obtained in an aqueous medium, meaning that more residual water might be entrapped in their structure. The thermal decomposition of pectin started above $200{ }^{\circ} \mathrm{C}$ (Fig. 3A), in agreement with the reported information about decomposition of polysaccharides [24-26]. The mass loss stage with a $T_{\text {on }}$ of $c a .364^{\circ} \mathrm{C}$ (Fig. 3B) can be explained considering that the mixture obtained between organic (pectin) and inorganic (iron) portions at the moment of obtaining the beads requires a higher calcination temperature to remove all the organic matter.

The size and zeta potential of the iron-pectin beads were analyzed by dynamic light scattering (DLS). The charge of the beads, no matter the solutions they were exposed to, was around 0 . In fact, the zeta potential was $-1.1 \pm 0.7 \mathrm{mV}$ for beads suspended in water, and $-1.2 \pm 0.9 \mathrm{mV}$ at the end of the simulated digestion. Regarding the particle size, as the target of the particles is the gut, only their size at the end of the process will be here discussed. After digestion, the smallest population had a Z-average size of $4.6 \pm 1.2 \mu \mathrm{m}$ with a polydispersity index of $5.3 \pm 1.4$. This leads to the conclusion that the digestion process disrupted the beads, reducing the average particle size when compared to the initial 1-2 mm shown in Fig. 1 . The very high polydispersity index (and size distribution) indicates a non-homogeneous particle population, most probably as result of the digestion process. Considering that ionotropic gels were prepared in acidic media, the stability of pectin gels is maximum at pH 4 [27]. Hence, the large size of the beads' pores after exposure to simulated gastric medium can be ascribed to swelling.

On the contrary, in alkali conditions the so-called $\beta$-elimination of galacturonic acid residues of pectins results in chain cleavage and very quick loss of viscosity and gelling properties [27,28]. Demethylation process has also been reported to occur in alkali conditions [29]. Therefore, the simulated intestinal digestion was the main process that disrupts the size of the beads in this work. These results would indicate that iron is released from the beads, undergoes oxidation, and can be found as a water-soluble Fe(III)-oligopectin complex.

\subsection{Iron absorption and transepithelial passage}

The total iron content of the beads is $2.06 \pm 0.01 \mathrm{mM}$. A low concentration of iron is released in saliva $(0.12 \mathrm{mM})$, and after exposure to gastric and intestinal conditions the iron concentration is 0.79 and $0.77 \mathrm{mM}$, respectively [12]. Fig. 4A depicts the uptake of the iron arriving to the intestine, by Caco-2/TC7 cells. The source of iron $\left[\mathrm{FeSO}_{4}\right.$ (control) or iron-pectin beads] did not have any significant effect on the mineral uptake (Fig. 4A). The average absorption of the metal was $13.98 \pm 2.53 \mu \mathrm{M}$, representing $6.98 \%$ of the total iron added to the cells, in agreement with other similar studies [30]. The values of iron absorption reached after $2 \mathrm{~h}$ of incubation were maintained during the experiment without significant differences over time. Iron accumulation is known to be a quick process in saturation conditions, with a rapid increase of iron uptake during the first 40-60 minutes. This leads to a plateau of iron concentration inside the cells [31]. The absorption of soluble free inorganic iron at an intestinal level occurs in the brush border of enterocytes. Whereas Fe(II) is directly absorbed, the absorption of Fe(III) is mediated by a divalent metal transporter 1 (DMT1). In that step, Fe(III) is firstly reduced to Fe(II), making it available for transport across the brush border membrane by DMT1 [32]. On the other hand, it has been demonstrated that nanoparticulated Fe(III) poly oxo-hydroxide (insoluble at duodenal $\mathrm{pH}$ ) and other nanosized iron particles ranging from $9 \mu \mathrm{m}$ to $50 \mathrm{~nm}$ can be uptaken by enterocytes using different endocytic pathways $[33,34]$. In this work, after digestion, the iron beads released free inorganic iron and part of the iron was retained in the partially digested beads, which exhibited an average Zsize of $4.6 \pm 1.2 \mu \mathrm{m}$ (see Section 3.1). Therefore, both mechanisms of iron uptake are plausible to incorporate the iron from the beads into Caco-2/TC7 cells.

The iron added to the apical pole of Caco-2/TC7 monolayers was recovered in the basal compartment, and it was proportional to the exposure time (Fig. 4B). During the first $4 \mathrm{~h}$ of incubation, no significant differences $\left(\mathrm{p}>0.05\right.$ ) between the iron passage from $\mathrm{FeSO}_{4}$ (control) and from the beads were observed. After that, the transport of iron arising from the beads was significantly higher than that of the iron from the control (Fig. 4B). Iron transport is a slower process than iron absorption. Depending on the source of iron, the maximum concentration of the metal in the basal chamber of in vitro models occurs after 4 or $24 \mathrm{~h}$ of incubation [35]. As iron transport across Caco-2/TC7 monolayers is a very low efficient process, only a small proportion (less than $2 \%$ ) of the total iron arising from the generally used sources of mineral, namely $\mathrm{FeSO}_{4}$ or Fe-citrate, is transported [35,36]. This 


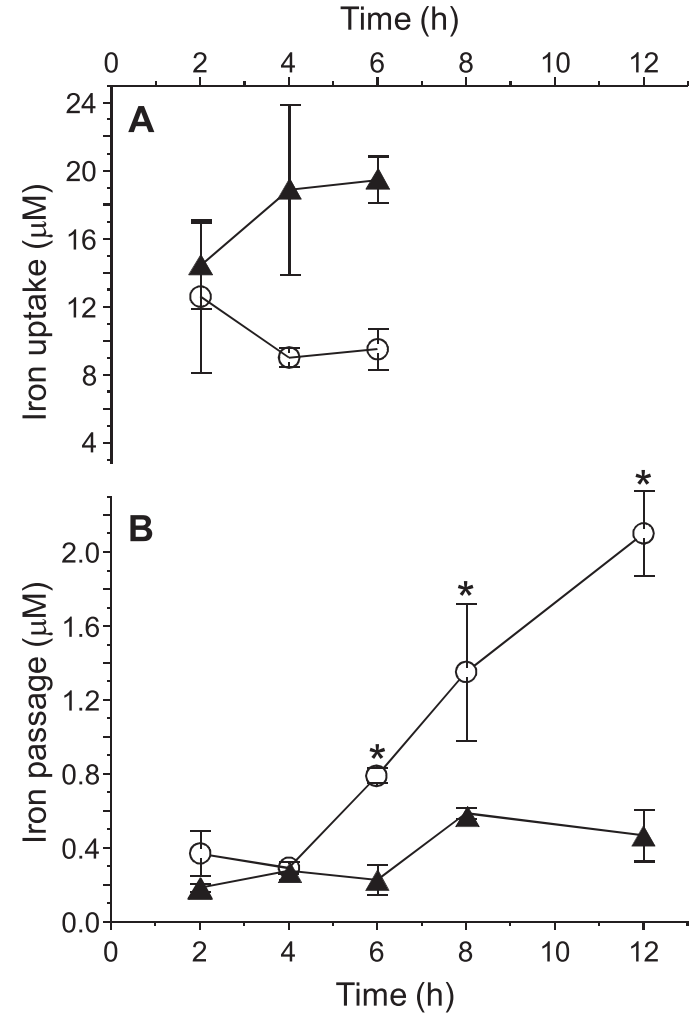

Fig. 4. A. Iron uptake in Caco-2/TC7 cells. Cells were incubated at different time points in DMEM containing two iron sources: $\mathrm{FeSO}_{4}$ (control, triangles) and the digested iron-pectin beads (circles). The final concentration of $\mathrm{Fe}$ in both conditions was $200 \mu \mathrm{M}$. Iron transport was expressed in $\mu \mathrm{M} \pm \mathrm{SD}$. B. Transepithelial passage of iron trough Caco-2/TC7 monolayers. Iron sources $\left[\mathrm{FeSO}_{4}\right.$ (triangles) or digested iron-pectin beads (circles)] were added to the upper compartment. The final concentration of $\mathrm{Fe}$ for both conditions was $200 \mu \mathrm{M}$. At different time points, the content of the basal compartment was removed and assayed for iron concentration. Iron transport was expressed in $\mu \mathrm{M} \pm \mathrm{SD}$. Asterisks indicate significant differences $(\mathrm{p}<0.05)$ between the iron concentration in the basal compartment for the two treatments at the same time point.

reflects the limited efficiency of in vivo iron transport. In this work, the incubation of Caco-2/TC7 cells with the digested beads showed to significantly increase the iron transport in comparison to the controls $\left(\mathrm{FeSO}_{4}\right)$, thus appearing as an interesting strategy to overcome the low efficiency of iron transport.

\section{Conclusion}

The development of stable beads containing natural dietary fiber (pectins) and an essential trace metal (iron) is the main achievement of this work. Iron deficiency is still a public health problem worldwide, and the incorporation of the metal to food matrices does not completely resolve the problem if iron is not properly transported. The significantly greater transport of iron compared to that of the mostly used sources of iron, convert the developed iron-pectin beads in novel and interesting sources of iron, opening several possibilities for their application in the food and pharmaceutical industries. Furthermore, the possibility of obtaining organic complexes of iron and natural fiber at a micron or sub-micron scale also opens the possibility of using them as functional ingredients in the formulation of food products, preserving the organoleptic properties.

\section{Competing interests}

The authors declare that they have no competing interests.

\section{Acknowledgments}

This project has received funding from the European Union's Horizon 2020 research and innovation programme under grant agreement $\mathrm{N}^{\circ}$ 777657, the Argentinean Agency for the Scientific and Technological Promotion (ANPCyT) [Projects PICT(2014)/0912; PICT start-up (2016)/4808, PICT(2017)/1344], FEDER (Programa Operacional Factores de Competitividade COMPETE), and FCTFundação para a Ciência e a Tecnologia (Project No. UID/FIS/04564/ 2016). Scanning Electron Microscopy was carried out at Service of Electron Microscopy and Microanalysis, Faculty of Engineering, UNLP, Argentina. Access to TAIL-UC facility (XRF measurements) funded under QREN-Mais Centro Project No. ICT 2009_02_012_1890 is also acknowledged. E.G., V.C.O. and A.G.-Z. are members of the research career CONICET. F.G. is doctoral fellow from ANPCyT. P.A. is a postdoctoral fellow and would like to thank FCT for her grant (REF: SFRH/ BPD/69410/2010).

\section{Appendix A. Supplementary data}

Supplementary material related to this article can be found, in the online version, at doi:https://doi.org/10.1016/j.colsurfb.2018.06.052.

\section{References}

[1] M.B. Zimmermann, R.F. Hurrell, Lancet Semin. 370 (2007) 511.

[2] P. Sharp, S.K. Srai, World J. Gastroenterol. 13 (2007) 4716.

[3] N. Abbaspour, R. Hurrell, R. Kelishadi, J. Res. Med. Sci. 19 (2014) 164

[4] R. Hurrell, Nutition Rev. 60 (2002) 7.

[5] S. Bourgeois, M. Gernet, D. Pradeau, A. Andremont, E. Fattal, Int. J. Pharm. 324 (2006) 2.

[6] T. Coviello, P. Matricardi, C. Marianecci, F. Alhaique, Control Release 119 (2007) 5.

[7] V.R. Sinha, R. Kumria, Int. J. Pharm. 224 (2001) 19.

[8] O. Munjeri, J.H. Collett, J.T. Fell, J. Control. Release 46 (1997) 273.

[9] L. Liu, M.L. Fishman, K.B. J. Kost, Hicks, Biomaterials 24 (2003) 3333.

[10] S. Das, K. Ng, Int. J. Pharm. 385 (2010) 20.

[11] A. Assifaoui, O. Chambin, P. Cayot, Carbohydr. Polym. 85 (2011) 388.

[12] F. Ghibaudo, E. Gerbino, V. Campodall' Orto, A. Gómez-Zavaglia, J. Funct. Foods 39 (2017) 299.

[13] Y. Ohkawara, M. Bamba, I. Nakai, S. Kinka, M. Masuda, Gastroenterology 44 (2018) 611.

[14] C.K. Yeung, R.E. Glahn, R.M. Welch, D.D. Miller, J. Food Sci. 70 (2005) 88.

[15] F. Martin-Dejardin, B. Ebel, G. Lemetais, H.N. Thi, P. Gervais, R. Cachon, Eur. J. Pharm. Sci. 49 (2013) 166.

[16] J. Grimoud, H. Durand, S. de Souza, P. Monsan, F. Ouarné, V. Theodorou, C. Roques, Int. J. Food Microbiol. 144 (2010) 42.

[17] R.A. Brant, Normos Mössbauer Fitting Program v.90, Wissel GmbH, Stanberg, Germany, 1994.

[18] E.A. Günter, O.V. Popeyko, Carbohydr. Polym. 147 (2016) 490.

[19] G.F. Oliveira, P.C. Ferrari, L.Q. Carvalho, R.C. Evangelista, Carbohydr. Polym. 82 (2010) 1004.

[20] K.L.B. Chang, J. Lin, Carbohydr. Polym. 43 (2000) 163.

[21] M. Narkar, P. Sher, A. Pawar, AAPS PharmSciTech 11 (2010) 267.

[22] F.G. Prezotti, B. Stringhetti, F. Cury, R.C. Evangelista, Carbohydr. Polym. 113 (2014) 286.

[23] C. Remuñan-López, R. Bodmeier, J. Control Release 44 (1997) 215.

[24] M.J. Zohuriaan, F. Shokrolahi, Polym. Test. 23 (2004) 575.

[25] J.F.A. Souto-Maior, A.V. Reis, L.N. Pedreiro, O.A. Cavalcanti, Polym. Int. (2010) 127.

[26] J. Aburto, M. Moran, A. Galano, E. Torres-García, J. Anal. Appl. Pyrol. 112 (2015) 94.

[27] P. Sriamornsak, Silpakorn Univ. Int. J. 3 (2003) 206.

[28] J.V. Díaz, G.E. Anthon, D.M. Barrett, J. Agric. Food Chem. 55 (2007) 5131.

[29] C.M.G.C. Renard, J.-F. Thibault, Carbohydr. Res. 286 (1996) 139.

[30] N.M. Scheers, A.B. Almgren, A.S. Sandberg, J. Nutr. Biochem. 25 (2014) 710.

[31] C. Halleux, Y. Schnelder, J. Cell. Physiol. 158 (1994) 17.

[32] T.M. Steele, D.M. Frazer, G.J. Anderson, IUBMB Life 57 (2005) 499.

[33] D.I.A. Pereira, B.I. Mergler, N. Faria, S.F.A. Bruggraber, M.F. Aslam, L.K. Poots, L. Prassmayer, B. Lönnerdal, A.P. Brown, J.J. Powell, PLoS One 8 (2013) e81250.

[34] A. Perfecto, C. Egly, E. Valsami-Jones, P. Sharp, E. Hilty, S. Fairweather-Tait, Nutrients 9 (2017) 359.

[35] L. Sánchez, M. Ismail, F.Y. Liew, J.H. Brock, Biochim. Biophys. Acta 1289 (1996) 291.

[36] M. Wen-Qiang, J. Wu, Z. Zhuo, H. Sun, M. Yue, J. Feng, Int. J. Agric. Biol. 15 (2013) 372. 